\title{
Material design self- efficacy Materyal tasarımı öz-yeterlik belief scale: a validity and inancı ölçeği: geçerlik ve reliability study güvenirlik çalışması ${ }^{1}$
}

\author{
Ebru Bakaç² \\ Raşit Özen ${ }^{3}$
}

\begin{abstract}
The aim of this study is to develop a scale which will be used to determine preservice teachers' material design self-efficacy beliefs. Draft scale consist of 74 items created as a result of the examination of Education Faculty curriculum and Instructional Technologies and Material Design course books were presented to the fifteen measurement and evaluation, computer and instructional technologies and curriculum development field experts opinions. Draft scale is reduced to 53 items according to field experts opinions. The participants of the study were 300 preservice teachers who were studying at Abant Izzet Baysal University in academic year 20132014. Participants were selected by using random sampling method. The construct validity of scale was tested by using exploratory and confirmatory factor analysis and a threefactor structure scale which accounts of $48 \%$ of total variance was reached. As a result of factor and item analysis, a 25 item-final scale was obtained. The cronbach alpha reliability coefficient of the scale was calculated as 0,92 . Those results show that this scale can be used as an appropriate measurement tool to preservice teachers' material design self-efficacy beliefs.
\end{abstract}

Özet

$\mathrm{Bu}$ araştırmanın amacı öğretmen adaylarının materyal tasarımı öz-yeterlik inanç düzeylerini belirlemek için kullanılacak bir ölçme aracı geliştirmektir. Eğitim Fakültesi öğretim programları ile Öğretim Teknolojileri ve Materyal Tasarımı ders kitaplarının incelenmesi sonucu oluşturulan 74 maddelik taslak ölçme aracı ölçme ve değerlendirme, bilgisayar ve öğretim teknolojileri ile program geliştirme alanlarında çalışan on beş uzmanin görüşüne sunulmuştur. Alan uzmanlarının görüşü sonucu taslak ölçeğin madde sayısı 53 olarak sinırlandırılmıştır. Araştırmanın çalışma grubunu 2013-2014 eğitim-öğretim yllında Abant İzzet Baysal Üniversitesi’nde öğrenim gören ve ÖTMT dersini daha önce almış olan 300 öğretmen adayı oluşturmuştur. Katıllimcilar tesadüfi örnekleme yöntemi ile belirlenmiştir. Ölçeğin yap1 geçerliği açımlayıcı ve doğrulayıcı faktör analizi yapılarak test edilmiş ve toplam varyansin \% 48'ini açıklayan üç boyutlu bir yapıya ulaşılmıştır. Faktör analizleri ve madde analizleri sonucunda 25 maddelik nihai ölçek elde edilmiştir. Ölçeğin Cronbach-Alfa güvenirlik katsayısı 0,92 olarak hesaplanmıştır. Elde edilen bu sonuçlar ölçeğin öğretmen adaylarının materyal tasarlamaya yönelik öz-

\footnotetext{
1 Bu çalışma birinci yazarın Doç.Dr. Raşit Özen danışmanlığında hazırladığı “Öğretmen Adaylarının Öğretim Teknolojileri ve Materyal Tasarımı Dersine Yönelik Tutumları, Yaratıcılık Algıları ve Öz-Yeterlik İnançlanı Arasındaki İlişki” adlı doktora tez çalışmasının bir bölümünü içermektedir.

2 Dr., ebruli 2239@hotmail.com

3 Doç. Dr., Abant İzzet Baysal University, Education Faculty, Department of Educational Sciences, ozen_r@ibu.edu.tr
} 
Keywords: material design, self-efficacy belief, yeterlik inançlarının ölçülmesi için uygun bir

preservice teachers, validity, reliability

(Extended English abstract is at the end of this document) ölçme aracı olarak kullanılabileceğini
göstermektedir.

Anahtar Kelimeler: materyal tasarım1, özyeterlik inanc1, öğretmen adayları, geçerlik, güvenirlik

\section{Giriş}

Sınıf etkinlikleri öğrencilerin öz-yeterlik inançlarını olumlu veya olumsuz bir şekilde etkilemektedir. $\mathrm{Bu}$ sebepten dolayı eğitim uygulamalarının sadece bilgi ve beceri kazandırma üzerine inşa edilmemesi, öğretim etkinliklerinin öğrencilerin kendi yeteneklerine yönelik inançları üzerindeki etkisine dikkat edilmesi, rekabete dayalı bir sınıf ortamı yerine işbirliğine dayalı bir öğrenme ortamı oluşturulması gerekmektedir (Bandura, 1997). Senemoğlu (2007)'na göre de öğretmenlerin öğrencilerin öz-yeterlik inançlarını güçlendirebilmesi için bireysel ihtiyaçlarına uygun öğretim yapmaları, çok çeşitli etkinliklere yer vermeleri, işbirliğine dayalı öğretim yaklaşımları kullanmaları ve öğrencileri birbirleriyle karşılaştırmamaları önemli görülmektedir. Öğretim Teknolojileri ve Materyal Tasarımı (ÖTMT) dersinde de bu ilkelere dikkat edilmesinin öğrencilerin derse yönelik öz-yeterlik inançlarını olumlu bir şekilde etkileyeceği, öz-yeterlik inançları olumlu olan öğrencilerin ise Öğretim Teknolojileri ve Materyal Tasarımı dersinde daha başarılı olacakları, özgün tasarımlar gerçekleştirecekleri düşünülmektedir. Araştırmacı tarafindan Öğretim Teknolojileri ve Materyal Tasarımı dersine yönelik yapılmıs araştırmalar incelendiğinde, bu çalışmaların genellikle Eğitim Fakültelerinin belli bölümlerinde okuyan öğrencilerle sınırlı kaldığ1 (Acer, 2011; Bektaş, Nalçacı ve Ercoşkun, 2009; Kolburan Geçer, 2010; Uyangör ve Ece, 2010), eğitimde teknoloji kullanımı konusuna yoğunlaşıldığı (Aşan, 2002; Betrus ve Molenda, 2002; Hu, Clark ve Ma, 2003); buna karşılık materyal tasarımı boyutunun dikkate alınmadığı, bu alanda geliştirilmiş ölçek sayısının yetersiz olduğu (Bursal ve Yiğit, 2012; Ünsal, 2011; Varank ve Ergün, 2009); geliştirilen bu ölçeklerde materyal tasarımı öz-yeterlik inancının belirlenmesine yer verilmediği veya ölçeklerin içerik yönünden yeterli olmadığı saptanmıştır. Araştırmacıların genellikle teknoloji kullanımı (Aşkar, 2004), bilgisayar ve internet kullanımına yönelik öz-yeterlilik inançları (Bircan, 2012; Özüt ve Tuncer, 2012) üzerine yoğunlaştıkları görülmektedir. Örneğin; Aşkar (2004)'ın eğitim yazılımı geliştirme öz-yeterlik algısına yönelik bir ölçme aracı geliştirdiği, Özüt ve Tuncer (2012)'nin sınıf öğretmeni adaylarının eğitsel internet kullanımı öz-yeterlik inançlarını belirlediği, Bircan (2012)'nin ise Türkçe öğretmen adaylarının öğretim teknolojileri kullanımına yönelik özgüvenlerini araşıırdı̆̆ bulgularına erişilmiştir. 
Öğretmen adaylarının teknoloji kullanımına yönelik becerilerinin geliştirilmesinin yanında öğretme öğrenme sürecinin vazgeçilmez bir parçası olan materyal tasarımına da gerekli önemin verilmesi gerekmektedir; çünkü öğretmen adayları meslek yaşamları boyunca mezun oldukları alana uygun materyalleri tasarlamak ve kullanmak durumundadırlar. Materyaller öğrencilerin dersi daha iyi algılamaları ve öğrenmeleri için vazgeçilmez unsurlardan biridir. Materyal kullanılarak yapılan öğretim sayesinde öğrenciler birden fazla duyu organını kullanarak öğrenme sürecine dahil olmakta, daha kalıcı ve izli yaşantılar geçirmektedirler (Seferoğlu ve Yağc1, 2001; Yalın, 2007). Sonuç olarak öğretmenlerin böyle bir sınıf ortamı yaratabilmeleri için materyal tasarlamayı bilmeleri gerekmektedir. Bu bağlamda bu araştırmanın amacı öğretmen adaylarının materyal tasarlamaya yönelik öz-yeterlik inançlarını belirleyebilecek bir ölçme aracı geliştirmektir.

\section{Yöntem}

Araştırmacı tarafindan geliştirilen "Materyal Tasarımı Öz-yeterlik İnancı Ölçeğı” öğretmen adaylarının materyal tasarımı öz-yeterlik inançlarını belirlemeyi amaçlamaktadır. Taslak ölçme aracı 2013-2014 akademik y1lında Abant İzzet Baysal Üniversitesi'nin çeşitli bölümlerinde öğrenim gören 300 öğretmen adayına uygulanmıştır.

\section{1. Çalışma Grubu}

Ölçeğin geçerlik ve güvenirlik çalışmasının yürütüldüğü grubun bölümlerine ve cinsiyetlerine ilişkin bilgiler Tablo 1'de sunulmuştur.

Tablo 1. Çalışmaya Dahil Edilen Öğretmen Adayı Sayıları

\begin{tabular}{|c|c|c|c|c|c|}
\hline \multirow{3}{*}{ Bölüm } & \multicolumn{4}{|c|}{ Cinsiyet } & \multirow{3}{*}{$\frac{\text { Toplam }}{\mathrm{f}}$} \\
\hline & \multicolumn{2}{|c|}{ Kadin } & \multicolumn{2}{|c|}{ Erkek } & \\
\hline & $\mathrm{f}$ & $\%$ & $\mathrm{f}$ & $\%$ & \\
\hline İngilizce Ö Ört. & 29 & 74,4 & 10 & 25,6 & 39 \\
\hline Sosyal Bilgiler Ö ğrt. & 21 & 56,8 & 16 & 43,2 & 37 \\
\hline Sinıf Öğrt. & 23 & 65,7 & 12 & 34,3 & 35 \\
\hline Resim Öğgrt. & 12 & 70,6 & 5 & 29,4 & 17 \\
\hline Fen ve Teknoloji Öğrt. & 25 & 89,3 & 3 & 10,7 & 28 \\
\hline Özel Eğitim Öğrt. & 16 & 44,4 & 20 & 55,6 & 36 \\
\hline Türkçe Öğrt. & 48 & 70,6 & 20 & 29,4 & 68 \\
\hline Matematik Öğrt. & 29 & 72,5 & 11 & 27,5 & 40 \\
\hline Toplam Öğrt. Adayı Sayısı & 203 & 67,7 & 97 & 32,3 & 300 \\
\hline
\end{tabular}


Tablo 1 incelendiğinde çalışma grubuna dahil edilen toplam (n=300) öğretmen adayının \% 67,7’ sini kadın öğretmen adaylarının ( $\mathrm{n}=203)$ ve \% 32,3’ünü ise erkek öğretmen adaylarının ( $\mathrm{n}=97)$ oluşturduğu görülmektedir.

\subsection{Materyal Tasarımı Öz-yeterlik İnancı Ölçeği’nin Geliştirilme Süreci}

Öz-yeterlik ölçekleri genellikle araştırmacı tarafindan belirlenen alan içine giren farklı seviyelerdeki görevleri yerine getirmeye yönelik olarak, bireylerin kendi yeterlik düzeylerine ilişkin inançlarını ölçmektedir. Bu ölçekler bireylerin kendi yeterliklerine ilişkin en üst ve alt alg1 sınırlarını belirlemeye yardımc1 olmaktadır (Bandura, 1989). Materyal Tasarımı Öz-yeterlik İnancı Ölçeği’nin geliştirilmesinde ilk adım olarak araştırmacı tarafindan alanyazın taraması yapılmış (Aşkar, 2004; Bursal ve Yiğit, 2012; Ünsal, 2011; Varank ve Ergün, 2009; Yanpar, 2009), ÖTMT dersine yönelik ders kitapları incelenmiş (Demirel ve Altun, 2007; İşman, 2011; Kaya, 2006; Sarıçoban ve Tavil, 2012; Seferoğlu ve Yağc1, 2001; Selvi, 2012; Sever, 2011; Uzunboylu, 2011; Yalın, 2007; Yanpar, 2011; Yıldız, 2004) ve materyal tasarımı ile ilgili olduğu düşünülen 74 ifadeden oluşan bir madde havuzu oluşturulmuştur. Araştırmacı tarafindan "Materyal Tasarımı Öz-yeterlik İnancı Ölçeği” nin ölçek maddelerinin tamamı olumlu olacak şekilde hazırlanmıştır; çünkü Bandura (2006)' ya göre özyeterlik inancı ölçekleri tek kutupludur ve sıfirdan başlayarak maksimum yeterlik düzeyine kadar ulaşmalıdırlar. Ayrıca ölçekler negatif madde içermemelidirler; çünkü bu tarz ölçeklerde tamamen yetersizim (0) düzeyinin altında ifadelere yer vermek mantıklı değildir (Bandura, 2006). Madde havuzu oluşturulduktan sonra ölçeğin yüzeysel (görünüş) geçerliği için araştırmacı tarafından Öğretim Teknolojileri ve Materyal Tasarımı (ÖTMT) dersini veren, Bilgisayar ve Öğretim Teknolojileri, Eğitimde Ölçme ve Değerlendirme ile Eğitimde Program Geliştirme alanlarında çalışan 15 öğretim üyesi ve öğretim elemanının ölçek ile ilgili görüşlerine başvurularak uzman görüşü alınmıştır. Bandura (2006)'nın da belirttiği gibi öz-yeterlik ölçekleri görünüş geçerliğine sahip olmalıdirlar.

Görünüş geçerliği ölçme aracının hangi özelliği ölçtüğü hakkındaki uzman görüşüne dayanır ve sayısal değerlerle belirlenmez, kanaatlere göre bir kabul söz konusudur. Konu alanı uzmanlarına başvurarak ölçme aracının kullanılacağı amaç için uygun olup olmadığına, gerekli veriyi toplayacak durumda olup olmadığına ilişkin görüş alınır (Tavşancıl, 2010). Bu süreçte yukarıda belirtilen konu alanı uzmanlarından ön deneneme formundaki maddeleri ölçeğin amacına uygun olarak değerlendirmeleri istenmiştir. Bu kapsamda mevcut maddelere farklı maddeler eklemeleri ya da var olan maddelerin durumu hakkında fikirlerini belirtmeleri talep edilmiştir. Konu alanı uzmanlarının taslak ölçeği değerlendirmesi sonucunda denemelik ölçekteki madde sayısının çok olduğu sonucuna ulaşılmış, bunun sonucunda araştırmacı tarafından 74 maddeden iki ya da üç boyutta birden yer 
alan maddeler bir defa yazılarak ön deneneme formundaki madde sayısının azaltılması yoluna gidilmiş olup uzman görüşlerine göre bazı maddeler ölçekten çıkarılmış ve birkaç yeni madde de ölçeğe eklenmiştir. Ayrıca uzman görüşleri doğrultusunda ölçeğin dil ve ifade yanlışları düzeltilmiş, dilbilgisi yönünden uygun hale getirilmiş ve bu işlem sonucunda 53 maddeden oluşan 5'li Likert tipi (1)'den “Hiç Katılmiyorum” (5)'e doğru “ Tamamen Katıllyorum” şeklinde derecelendirilen Materyal Tasarımı Öz-yeterlik İnancı Ölçeği oluşturulmuştur. Ölçeğin yapı geçerliği ve güvenirlik çalışmalarının yapılabilmesi için 53 maddeden oluşan ölçek ÖTMT dersini daha önce almış olan öğretmen adaylarına uygulanmak üzere pilot uygulamaya sunulmuştur.

Araştırmacı tarafindan bu çalışmanın amacı doğrultusunda geliştirilen Materyal Tasarımı Öz-yeterlik İnancı Ölçeği’nin ön uygulamasının yapılabilmesi için üçüncü sınıf ve dördüncü sınıf ikinci öğretim öğrencilerinden oluşan 300 kişilik bir grup öğretmen adayı random yolla seçilmiştir. Açımlayıcı Faktör Analizi yapabilmek için en az 300 kişilik bir örneklem sayısının uygun olduğu genel kural olarak ortaya konmaktadır (Çokluk, Şekercioğlu ve Büyüköztürk, 2010). Öğretmen adaylarına araştırmacı tarafından ölçekler hakkında bilgi verilmiş, çalışmanın amacına ulaşması için dikkat etmeleri gereken hususların altı çizilmiştir. Ölçekler, uygulamanın yapıldığı sırada dersi veren ders sorumlusu öğretim elemanlarının gözetiminde uygulanmış veya ders sorumlusu öğretim elemanlarına araştırma hakkında bilgi verilerek ölçeklerin uygulanması işlemi sırasında uyulması gereken kuralları öğretmen adaylarına hatırlatmaları istenmiştir. Büyük bir çoğunluğu daha önce ÖTMT dersinin içeriği konusunda bilgi sahibi olan öğretim elemanları öğretmen adaylarına gerekli açıklamalarda bulunarak öğretmen adayları tarafindan ölçeklerin daha uygun bir şekilde doldurulmaları konusunda yardımcı olmuşlardır.

\section{Bulgular}

Araştırmacı tarafından Materyal Tasarımı Öz-yeterlik İnancı Ölçeği’nin yap1 geçerliğini belirleyebilmek için SPSS 22 programı kullanılarak açımlayıcı faktör analizi (AFA) ve Lisrel 8.51 programı kullanılarak doğrulayıcı faktör analizi (AFA) yapılmıştır. Örneklem büyüklüğü açısından faktör analizi için veri yapısının uygunluğunu test etmeye yönelik olarak KMO (Kaiser-MeyerOlkin) testi sonucu dikkate alınmaktadır. Değerin yüksek olması ölçekteki her bir değişkenin diğer değişkenler tarafından mükemmel bir şekilde tahmin edilebileceği anlamına gelmektedir. Değerin ,50'den düşük olması analize devam edilemeyeceği anlamına gelmektedir (Çokluk, Şekercioğlu ve Büyüköztürk, 2010). Bu araştırmada araştırmacı tarafindan yapılan açımlayıcı faktör analizi sonucunda KMO (Kaiser-Meyer-Olkin) değerinin ,93 ve Barlett testi ki-kare değerinin 8074,24 ve $\mathrm{p}=0.00$ değerinin anlamlı olduğu, bu bağlamda veri yapısının açımlayıcı faktör analizi yapabilmek için yeterli olduğu değerlendirmesi yapılabilir (bkz. Tablo 2). 

Journal of Human Sciences, 12(2), 461-476. doi: 10.14687/ijhs.v12i2.3341

Tablo 2. KMO (Kaiser-Meyer-Olkin) Ve Barlett Testi Sonuçları

\begin{tabular}{ccc}
\hline \multicolumn{2}{c}{ Kaiser-Meyer-Olkin (KMO) } & ,931 \\
\hline Bartlett's Test & Ki-kare & 8074,24 \\
& sd & 1378 \\
& $\mathrm{p}$ &, 000 \\
\hline
\end{tabular}

Temel bileşenler analiz (Principal Component Analysis) kullanılarak faktör analizi yapılmış ve ölçeğin kaç faktörden oluştuğu saptanmıştır. Faktör analizi sonucunda öz-değeri 1'in üzerinde olan 12 faktör tespit edilmiştir. Araştırmacı tarafindan varimax döndürme tekniği kullanılarak faktör analizi yeniden yapılmış ve maddelerin üç faktör altında toplandıkları görülmüştür. Varimax döndürme tekniği basit yapıya ulaşmada faktör yükleri matrisinin sütunlarına öncelik vermekte, analiz işlemi sırasında her sütundaki bazı yük değerleri 1'e yaklaştırllırken, geriye kalan çok sayıda değer ise 0'a yaklaştırlmaktadır (Çokluk, Şekercioğlu ve Büyüköztürk, 2010). Faktör yüklerinin incelenmesinde 0,32 değeri kesme noktası olarak tayin edilmiştir. Açılklanan varyansın da \% 30 ve daha fazla olması uzmanlarca yeterli olarak kabul edilmekte ve bir maddenin iki yüksek yük değeri arasındaki farkın en az .10 olması önerilmektedir (Büyüköztürk, 2011). Araştırmacı tarafindan yapılan analiz sonucunda faktör yük değeri 0,32'nin altında kalan madde olmadığ1 tespit edilmiştir. Ancak iki yüksek yük değerleri arasındaki fark < 10 olan ve birden fazla faktöre yük verdiği belirlenen 1, 4, 5, 12, 13, 14, 15, 16, 19, 23, 24, 25, 28, 29, 34, 35, 36, 37, 38, 40, 41, 43, 45, 48, 50, 51, 52, 53 numaralı maddeler teker teker ölçekten çıkarılarak her defasında faktör analizi tekrar edilmiştir. En sonunda 25 maddeden oluşan ve toplam varyansın \% 48, 34’ ünü açıklayan üç faktörlü bir yapıya ulaşılmıştır. Birinci faktörün toplam varyansın \% 21, 01’ ini açıkladığ1 ve faktör yüklerinin .74 ile .55 arasında değiştiği görülmektedir. İkinci faktörün toplam varyansın \% 14,73’ ünü açılkadığ1 ve faktör yüklerinin .67 ile .51 arasında değiştiği; üçüncü faktörün de toplam varyansın \% 12,59’unu açılkladığı ve faktör yüklerinin .67 ile .57 arasında değiştiği görülmüştür. En son yapılan faktör analizi sonuçlarına göre faktör yük değerleri Tablo 3’te gösterilmiştir. 
Tablo 3. Materyal Tasarımı Öz-Yeterlik Inancı Ölçeğine Ait Faktör Yük Değerleri

\begin{tabular}{cccc}
\hline \multirow{2}{*}{ Madde no } & \multicolumn{3}{c}{ Faktörler } \\
\cline { 2 - 4 } M14 & 1 & $\mathbf{2}$ & $\mathbf{3}$ \\
M17 &, 687 & & \\
M16 &, 665 & & \\
M20 &, 639 & & \\
M23 &, 611 & \\
M18 &, 605 & & \\
M24 &, 596 & \\
M21 &, 589 & & \\
M19 &, 581 & & \\
M15 &, 577 & & \\
M13 &, 554 &, 672 & \\
M12 &, 553 &, 671 & \\
M11 & &, 669 & \\
M10 & &, 646 &, 609 \\
M8 & &, 597 & \\
M9 & &, 547 &, 667 \\
M7 & &, 510 & \\
M25 & & & \\
M22 & & & \\
M5 & & & \\
M2 & & & \\
M1 & & & \\
M4 & & & \\
M3 & & & \\
M6 & & & \\
Toplam & & & \\
Varyans & & & \\
\%48,34 & & & \\
& & & \\
\hline
\end{tabular}

Açımlayıcı faktör analizi sonucunda oluşan faktörlerden 14, 17, 16, 20, 23, 18, 24, 21, 19, 15, 13, 12 numaralı maddelerin toplandığı ve 12 maddeden oluşan faktör incelendiğinde genellikle bilgisayarda materyal tasarımı ilgili maddeleri içerdiği görülmüş (bkz. Tablo 3) ve bu faktör araştırmacı tarafindan "bilgisayarda materyal hazırlama" şeklinde isimlendirilmiştir. Bu faktörde yer alan maddelere örnek olarak "Madde 12: Sunumu żemin (arka plan) ve șekiller arasinda žt renkler kullanarak tasarlayabilirim." verilebilir. Ölçekte yer alan 11, 10, 8, 9, 7, 25, 22 numaralı maddelerin toplandığ ve 7 maddeden oluşan faktör incelendiğinde ise genellikle modellerin geliştirilmesi ile ilgili maddeleri içerdiği tespit edilmiş (bkz. Tablo 3.5) ve bu faktör araştırmacı tarafindan "üc boyutlu materyal tasarmm” şeklinde isimlendirilmiştir. Bu faktörde yer alan maddelere örnek olarak "Madde 11: Gerreek bir arac gerecin ögrenciler için anlaml bir modelini oluşturabilirim.” verilebilir. Son olarak ise 5, 2, 1, 4, 3, 6 numaralı maddelerin toplandığ1 ve 6 maddeden oluşan faktörün genellikle görsel öğelere yönelik maddeleri içerdiği saptanmış (bkz. Tablo 3) ve bu faktör araştırmacı tarafindan "iki boyutlu materyal tasarımı" 
şeklinde isimlendirilmiştir. Bu faktörde yer alan maddelere örnek olarak "Madde 3: Görselleri formal denge olusturacak sekilde yerlestirebilirim.” verilebilir.

Materyal Tasarımı Öz-yeterlik İnancı Ölçeği’nde bulunan alt boyutlar arasındaki ilişkiler incelenmiş ve ölçeğin üç alt boyutu arasında yüksek düzeyde ilişki olduğu görülmüştür (bkz. Tablo 4).

Tablo 4. Materyal tasarımı öz-yeterlik inancı ölçeği faktörler arası korelasyon katsayıları

\begin{tabular}{lccc}
\hline Alt Boyutlar & BMH & ÜBMT & İBMT \\
\hline BMH & 1 & & \\
ÜBMT &, $654^{* *}$ & 1 & \\
İBMT &, $708^{* *}$ &, $603^{* *}$ & 1 \\
\hline
\end{tabular}

**. $\mathrm{p}<0.01$

Not: BMH: Bilgisayarda materyal hazırlama; ÜBMT: Üç boyutlu materyal tasarımı; İBMT: İki boyutlu materyal tasarımı)

Materyal Tasarımı Öz-yeterlik İnancı Ölçeği’nin “Bilgisayarda Materyal Hazırlama” (BMH) alt boyutu ile "Üç Boyutlu Materyal Tasarımı" (ÜBMT) alt boyutu arasında yüksek düzeyde (r: 0,65) bir ilişki; "Bilgisayarda Materyal Hazırlama" $(\mathrm{BMH})$ alt boyutu ile "İki Boyutlu Materyal Tasarımı" (IBMT) alt boyutu arasında yüksek düzeyde (r: 0,71) bir ilişki; "Üç Boyutlu Materyal Tasarımı" (ÜBMT) alt boyutu ile "İki Boyutlu Materyal Tasarım»" (IBMT) alt boyutu arasında da yüksek düzeyde (r: 0,60) bir ilişki olduğu saptanmıştır. Bu bağlamda ölçekte yer alan üç faktör arasında güçlü bir ilişki olduğunu söylemek mümkündür.

Doğrulayıcı faktör analizi için araştırmacı tarafindan Ki-Kare Uyum Testi, karşılaştırmalı uyum indeksi (CFI), normlaştırılmış uyum indeksi (NFI), normlaştırılmamış uyum indeksi (NNFI) göreli uyum indeksi (RFI), fazlalık uyum indeksi (IFI), tahmin hatalarının ortalamasının karekökü (RMSEA) ve standartlaştırılmış hata kareleri ortalamasının karekökü (SRMR) uyum indeksleri incelenmiştir. RMSEA için .08 ve aşağı değerler iyi uyuma .08 ile .10 arası değerler zayıf uyuma işaret etmektedir (Hooper, Coughlan ve Mullen, 2008). CFI, NFI, RFI ve IFI indeksleri için 0.90 değeri kabul edilebilir uyuma ve 0.95 değeri mükemmel uyuma işaret etmektedir (Bentler ve Bonett, 1980; Hu ve Bentler, 1999). RMR için 0.05’ten küçük değerler iyi uyumu, 0.08'den küçük değerler ise kabul edilebilir uyumu (Hu ve Bentler, 1999); NNFI için 0.97 ile 1.00 arasındaki değerler iyi uyumu 0.95 ile 0.97 arasındaki değerler kabul edilebilir uyumu göstermekte; büyük örneklemler için $\mathrm{X}^{2} /$ sd değerinin 3'ün altında olması mükemmel uyuma, 5'in altında olması orta düzeyde uyuma karş1lık gelmektedir (Kline, 2005).

Açımlayıcı Faktör Analizi (AFA) sonucunda 25 madde ve 3 faktörden oluşan yapının doğruluğunu sınamak için doğrulayıcı faktör analizi yapılmış ve sonuçlar Şekil 1'de sunulmuştur. 


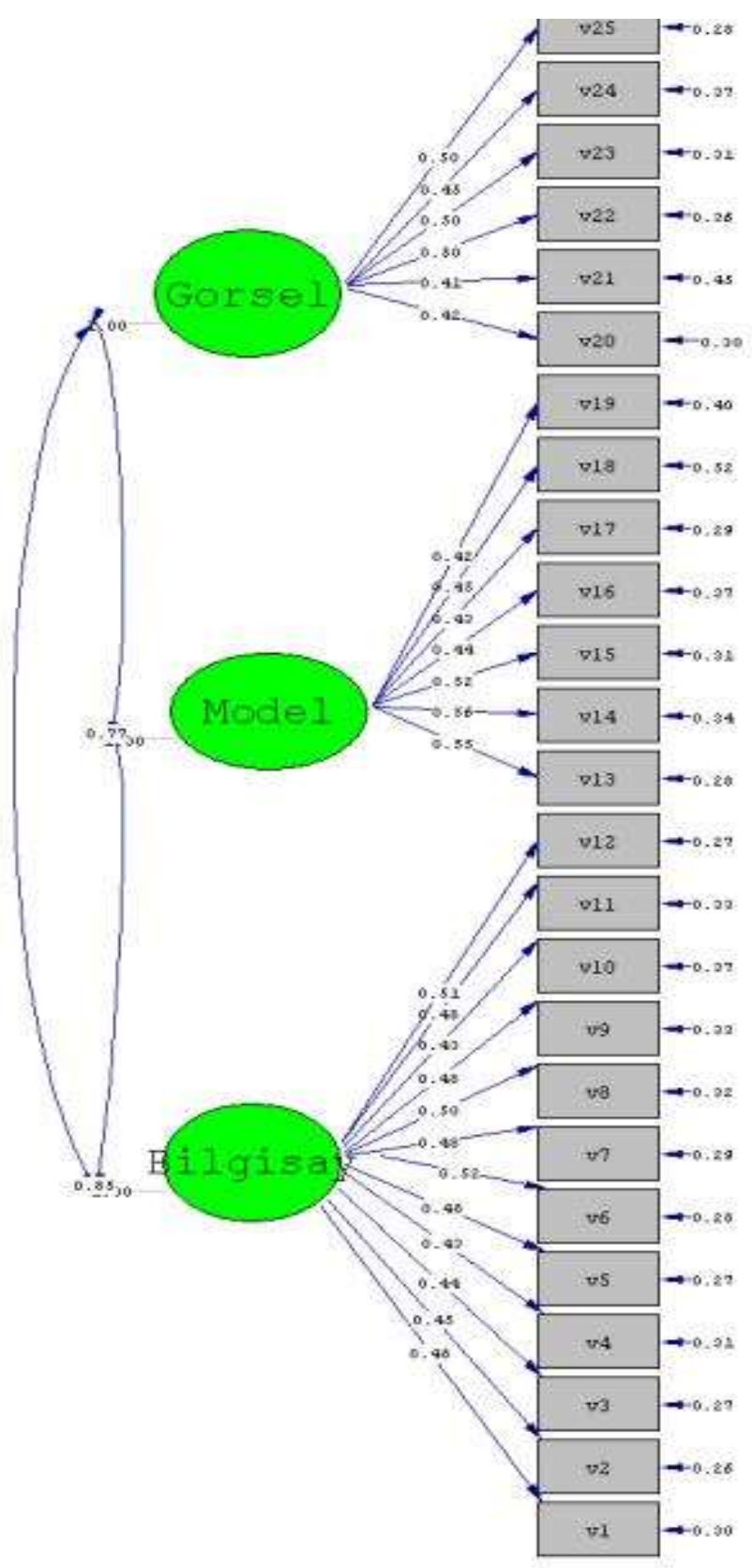

Şekil 1. Materyal Tasarımı Öz-Yeterlik Inancı Ölçeği Doğrulayıc1 Faktör Analizi

Doğrulayıcı faktör analizi (DFA)'den elde edilen modelin uyum indeksleri incelendiğinde Ki-kare değerinin $\left(\mathrm{X}^{2}=654.62, \mathrm{~N}=381, \mathrm{sd}=272, p=0.00\right)$ olduğu görülmektedir. Bu değerlerin birbirine oranlanmas1 sonucu $\mathrm{X}^{2} / \mathrm{sd}=654.62 / 272=2,40$ bulunmuştur. Bu çerçevede $\mathrm{X}^{2} / \mathrm{sd}$ değerinin mükemmel düzeyde uyum verdiği görülmektedir. Uyum indeksi değerleri ise RMSEA $=.061, \mathrm{NFI}=$ 
$.95, \mathrm{NNFI}=.95 \mathrm{CFI}=.95, \mathrm{IFI}=.90, \mathrm{RFI}=.93, \mathrm{RMR}=.052, \mathrm{GFI}=.90$ ve $\mathrm{AGFI}=.93$ olarak bulunmuştur. Bu uyum indeksi değerleri modelin iyi uyum verdiğini göstermektedir. Bunun sonucu olarak ise araştırmacı tarafından kurulan yapının doğrulandığı sonucuna ulaşılabilir.

Doğrulayıcı faktör analizi sonucunda kritik $\mathrm{N}$ değerinin $\mathrm{N}=197.96$ olduğu görülmektedir. $\mathrm{Bu}$ bağlamda faktör analizi için gerekli örneklem büyüklüğünün en az 198 kişi olması gerektiği ve örnekleme dahil edilen 381 kişinin faktör analizi için gerekli olan sayının üzerinde olduğu söylenebilir. Materyal tasarımı öz-yeterlik inancı ölçeği için yapılan açımlayıcı ve doğrulayıcı faktör analizi sonucunda 25 maddeden ve üç faktörden oluşan nihai ölçek elde edilmiştir.

Araştırmacı tarafindan "Materyal Tasarımı Öz-Yeterlik İnancı Ölçeği’nin” güvenirlik çalışması için Cronbach Alfa iç tutarlılık katsayısı hesaplanmıştır. Bu bağlamda araştırmacı tarafından yapılan güvenirlik analizi sonucunda "Materyal Tasarımı Öz-yeterlik İnanc1 Ölçeği’nin” bütününe ilişkin Cronbach Alfa iç tutarlılık katsayısı 0,92 olarak hesaplanmıştır. Tablo 5 incelendiğinde ölçeğin birinci alt boyutuna ilişkin (Bilgisayarda Materyal Hazırlama) Cronbach Alfa değeri 0,89 olarak; ikinci alt boyutuna ilişkin (Üç Boyutlu Materyal Tasarımı) Cronbach Alfa değeri 0,82 ve üçüncü alt boyutuna ilişkin (İki Boyutlu Materyal Tasarımı) Cronbach Alfa değeri 0,79 olarak bulunmuştur.

Tablo 5. Materyal Tasarımı Öz-Yeterlik Inancı Ölçeği’nin Tamamına Ve Alt Boyutlarına Ait Cronbach Alfa Değerleri

\begin{tabular}{ccc}
\hline Boyut ad1 & Madde Sayıs1 & Cronbach Alfa değeri \\
\hline Bilgisayarda Materyal Hazırlama & 12 & 0,89 \\
Ǘç Boyutlu Materyal Tasarımı & 7 & 0,82 \\
İki Boyutlu Materyal Tasarımı & 6 & 0,79 \\
Ölçeğin Tamamı & 25 & 0,92 \\
\hline
\end{tabular}

Şencan (2005)'a göre bilimsel içerikli çalışmalarda güvenirlik için 0,70 ve üzerinde bir iç tutarl1lık katsayısı yeterli görülür iken ilgi ve yetenek türü araştırmalarda kullanılacak ölçeklerde en az 0,85 düzeyinde bir güvenirlik katsayısı aranmaktadır. Buna göre ölçeğin tüm alt boyutları ve tamamına yönelik Cronbach Alpha değerinin 0.70’in üzerinde olduğu görülmektedir. Bu bağlamda ölçeğin iç tutarlık bakımından uygun olduğu söylenebilir.

Madde analizi kapsamında başvurulan bir başka yol ise testin toplam puanlarına göre oluşturulan alt \% 27 ve üst \% 27’lik grupların madde ortalama puanları arasındaki farkların ilişkisiz t-testi kullanılarak sınanmasıdır. İstendik yönde gözlenen farkların anlamlı çıkması testin iç tutarlılığının bir göstergesi olarak değerlendirilmektedir (Büyüköztürk, 2011). Materyal Tasarımı Öz-Yeterlik İnanc1 Ölçeği’ne yönelik olarak yapılan madde analizi sonuçları Tablo 6'da gösterilmiştir. 
Tablo 6. Materyal Tasarımı Öz-Yeterlik Inancı Ölçeği’ne Ait Madde Analizi Sonuçları

\begin{tabular}{|c|c|c|c|}
\hline $\begin{array}{l}\text { Madde } \\
\text { No }\end{array}$ & & $\begin{array}{l}\text { Madde Toplam } \\
\text { Korelasyonlan }\end{array}$ & $\begin{array}{l}\text { t-değeri } \\
(\text { Alt } \% 27- \\
\text { Üst } \% 27) \\
\end{array}$ \\
\hline 1 & Materyalde kullanılacak uygun yazı boyutunu belirleyebilirim. & ,56 & 13,98 \\
\hline 2 & Materyali uygun şekilde depolayabilirim. &, 51 & 12,65 \\
\hline 3 & $\begin{array}{l}\text { Görselleri formal denge (simetrik) oluşturacak şekilde } \\
\text { yerleştirebilirim. }\end{array}$ & ,56 & 10,98 \\
\hline 4 & $\begin{array}{l}\text { Sözel verilere uygun grafik türünü (sütun, pasta vb...) } \\
\text { seçerek kullanabilirim. }\end{array}$ & ,56 & 12,71 \\
\hline 5 & WordArt kullanarak içeriğe uygun bir başlık oluşturabilirim. & ,64 & 12,63 \\
\hline 6 & $\begin{array}{l}\text { Anlamlı bir bütün oluşturmak için ilişkili öğeleri yakın, } \\
\text { ilişkisiz öğeleri uzak olacak şekilde yerleştirebilirim. }\end{array}$ & ,58 & 13,03 \\
\hline 7 & $\begin{array}{l}\text { Materyali öğrencilerin yaratıcı düşünme becerilerini } \\
\text { geliştirebilecek şekilde tasarlayabilirim. }\end{array}$ & ,54 & 12,55 \\
\hline 8 & Modeli gerçeğine benzer şekilde oluşturabilirim. & ,61 & 13,79 \\
\hline 9 & $\begin{array}{l}\text { Materyalde farklı şekilleri bir araya getirerek anlamlı bir } \\
\text { bütün oluşturabilirim. }\end{array}$ & ,59 & 12,15 \\
\hline 10 & $\begin{array}{l}\text { Modeli her öğrencinin kullanımına uygun olacak şekilde } \\
\text { tasarlayabilirim. }\end{array}$ & ,62 & 9,99 \\
\hline 11 & $\begin{array}{l}\text { Gerçek bir araç-gerecin öğrenciler için anlamlı bir modelini } \\
\text { oluşturabilirim. }\end{array}$ & ,58 & 11,22 \\
\hline 12 & $\begin{array}{l}\text { Sunumu zemin (arka plan) ve şekiller arasinda zit renkler } \\
\text { kullanarak tasarlayabilirim. }\end{array}$ & 66 & 14,15 \\
\hline 13 & $\begin{array}{l}\text { Materyal üzerindeki önemli öğeye dikkat çekmek için okla } \\
\text { gösterme, temel öğeyi büyük yapma gibi yönlendirme } \\
\text { ilkelerini kullanabilirim. }\end{array}$ & ,56 & 12,61 \\
\hline 14 & Materyalde kullanilacak uygun yazı tipini belirleyebilirim. &, 57 & 13,58 \\
\hline 15 & $\begin{array}{l}\text { Sunuda kullanılan dili öğrenci hazır bulunuşluk düzeyine } \\
\text { uygun şekilde belirleyebilirim. }\end{array}$ & ,56 & 10,89 \\
\hline 16 & $\begin{array}{l}\text { Sunuda bulunan önemli öğelere dikkat çekmek için öğeyi } \\
\text { kalınlaşturma, farklı renk ve boyut kullanma gibi vurgu } \\
\text { ilkelerini kullanabilirim. }\end{array}$ & 66 & 9,88 \\
\hline 17 & $\begin{array}{l}\text { Kelime işlemci programını (Word) kullanarak ders } \\
\text { kazanımlarına uygun test, ödev ve alıştırma ömekleri } \\
\text { tasarlayabilirim. }\end{array}$ & 62 & 11,21 \\
\hline 18 & $\begin{array}{l}\text { İki boyutlu bir materyale dersin kazanımlanna uygun bir } \\
\text { başlik yazabilirim. }\end{array}$ & ,61 & 8,24 \\
\hline 19 & $\begin{array}{l}\text { Kelime işlemci veya sunu programlanında hazırlanan metnin } \\
\text { kenar boşluklarını, başlık ve metin arası boşlukları, satırlar } \\
\text { arası boşlukları uygun şekilde ayarlayabilirim. }\end{array}$ & 67 & 10,37 \\
\hline 20 & $\begin{array}{l}\text { Görseller arasındaki ilişkiyi oklar ve çizgiler kullanarak } \\
\text { yansitabilirim. }\end{array}$ & 61 & 9,39 \\
\hline 21 & $\begin{array}{l}\text { Materyali öğrencinin eğitim ihtiyacına yönelik olarak } \\
\text { tasarlayabilirim. }\end{array}$ & 64 & 9,07 \\
\hline 22 & $\begin{array}{l}\text { Modeli söküp takılabilen parçalardan oluşacak şekilde } \\
\text { tasarlayabilirim. }\end{array}$ & ,53 & 9,76 \\
\hline 23 & $\begin{array}{l}\text { Materyalin rengini grubun yaş özelliklerini dikkate alarak } \\
\text { seçebilirim. }\end{array}$ & 61 & 11,11 \\
\hline 24 & $\begin{array}{l}\text { Kelime işlemci programında hazırlanan materyallerin } \\
\text { üzerinde öğrenci ilgisini uyandıracak resim, şekil ve simgeler } \\
\text { oluşturabilirim. }\end{array}$ & 64 & 9,99 \\
\hline 25 & $\begin{array}{l}\text { Materyali öğrencilerin eleştirel düşünme becerilerini } \\
\text { geliștirebilecek șekilde tasarlayabilirim. }\end{array}$ & ,53 & 13,62 \\
\hline
\end{tabular}


Madde analizinden elde edilen bulgular sonucunda ölçeğin maddelerine ilişkin düzeltilmiş madde toplam korelasyonlarının .51 ile .67 arasında değerler aldığı belirlenmiştir. Ayrıca ilişkisiz t-testi sonucuna göre ölçekten elde edilen toplam puanlara göre oluşturulan alt \% 27 ve üst \% 27 grupların madde ortalama puanları arasındaki farkların anlamlı oldukları ve Materyal Tasarımı Öz-Yeterlik İnancı Ölçeği'nin iç tutarlılı̆ga sahip olduğu söylenebilir.

\section{Sonuç}

$\mathrm{Bu}$ araştırma kapsamında öğretmen adaylarının materyal tasarlamaya yönelik öz-yeterlik inanç düzeylerini belirleyen bir ölçme aracı geliştirilmiştir. Taslak ölçek daha önce ÖTMT dersini almış olan 300 öğretmen adayına uygulanmış ve gerekli analizler yapılmıştır. Faktör Analizi yapabilmek için en az 300 kişilik bir örneklem sayısının uygun olduğu genel kural olarak ortaya konmaktadır (Çokluk, Şekercioğlu ve Büyüköztürk, 2010). Ölçeğin yap1 geçerliği açımlayıcı ve doğrulayıcı faktör analizi yapılarak test edilmiştir. Açımlayıcı faktör analizi sonucunda ölçeğin bilgisayarda materyal hazırlama, üç boyutlu materyal tasarımı ve iki boyutlu materyal tasarımı olmak üzere üç alt boyuttan oluştuğu belirlenmiştir. Ölçeğin üç alt boyutu toplam varyansın \% 48,34'ünü açıklamaktadır. "Bilgisayarda Materyal Hazırlama” alt boyutundaki maddelerin faktör yükleri .55 ile .74 arasında değişmekte ve toplam varyansın \% 21,01' ini açıklamaktadır. "Üç Boyutlu Materyal Tasarımı” alt boyutundaki maddelerin faktör yükleri .51 ile .67 arasında değişmekte ve toplam varyansın \% 14,73’ünü açıklamaktadır. “İki Boyutlu Materyal Tasarımı” alt boyutundaki maddelerin faktör yükleri .57 ile .66 arasında değişmekte ve toplam varyansın \% 12,59’unu açıklamaktadır. DFA sonucuna göre uyum indeksi değerleri RMSEA $=.061, \mathrm{NFI}=.95, \mathrm{NNFI}=.95 \mathrm{CFI}=.95$, IFI $=.90$, $\mathrm{RFI}=.93, \mathrm{RMR}=.052$, GFI $=.90$ ve $\mathrm{AGFI}=.93$ olarak bulunmuştur. Bu uyum indeksi değerleri modelin iyi uyum verdiğini göstermektedir. Çünkü RMSEA için .08 ve aşağı değerler iyi uyumu .08 ile .10 arası değerler zayıf uyumu (Hooper, Coughlan ve Mullen, 2008); CFI, NFI, RFI ve IFI değerleri için de 0.90 değeri kabul edilebilir uyumu ve 0.95 değeri mükemmel uyumu işaret etmektedir (Bentler ve Bonett, 1980; Hu ve Bentler, 1999). Bu bağlamda 25 maddeden oluşan nihai ölçeğin uygun bir yapıya sahip olduğu sonucuna ulaşıldığı söylenebilir. İç tutarlılık (Cronbach-Alfa) güvenirlik katsayısı ölçeğin tamamı için 0,92 olarak hesaplanmış, alt boyutları için ise bu değerin 0,79 ve 0,89 arasında değiştiği görülmüştür. Şencan (2005)'a göre bilimsel içerikli çalışmalarda güvenirlik için 0,70 ve üzerinde bir iç tutarlılık katsayısı yeterli görülür iken ilgi ve yetenek türü araştırmalarda kullanılacak ölçeklerde en az 0,85 düzeyinde bir güvenirlik katsayısı aranmaktadır. Buna göre ölçeğin tüm alt boyutları ve tamamına yönelik Cronbach Alpha değerinin 0.70' in üzerinde olduğu görülmektedir. Bu bağlamda ölçeğin iç tutarlık bakımından uygun olduğu söylenebilir. Sonuç olarak 
Materyal tasarımı öz-yeterlik inancı ölçeğı’ nin geçerli ve güvenilir bir ölçme aracı olduğu söylenebilir.

\section{Kaynakça}

Acer, D. (2011). Okulöncesi öğretmen adaylarının materyal geliştirme dersine ilişkin görüşlerinin incelenmesi. İlkögretim Online, 10(2), 421-429.

Aşan, A. (2002). Pre-service teachers use of technology to create insructional materials: A schoolcollege partnership, technology, pedagogy and education. Pedagogy and Education, 11 (2), 217232.

Aşkar, P. (2004). Eğitim yazılımı geliştirme öz-yeterlik algısı ölçeği. Eğgitim Bilimleri ve Uygulama, 3 (6), 259-274.

Bandura, A. (1989b). Social cognitive theory. In R. Vasta (Eds.), Annals of child development: Six theories of child development,6, (pp. 1-60). Greenwich: JAI Press.

Bandura, A. ( 1997). Self-efficacy: The exercise of control. (7.edt). Newyork: Freeman and Company.

Bandura, A. (2006). Guide for constructing self-efficacy scales. In F. Pajares ve T. Urdan (Eds.), Self-efficacy beliefs of adolescents, 5, (pp. 307-337). Greenwich: Information Age Publishing.

Bektaş, F., Nalçacı, A. ve Ercoşkun, H. (2009). Sınıf öğretmeni adaylarının “öğretim teknolojileri ve materyal geliştirme/tasarımı” dersinin kazanımlarına ilişkin görüşleri. Kuramsal Eğitimbilim, 2 (2), 19-31.

Bentler, P. M. and Bonett, D. G. (1980). Significance tests and goodness of fit in the analysis of covariance structures. Psychological Bulletin, 88 (3), 588-606.

Betrus, A. K. and Molenda, M. (2002). Historical evolution of instructional technology in teacher education programs. Techtrends For Leaders in Education and Training, 46 (5), 18-21.

Bircan, E. (2012). Türkçe öğretmeni adaylarının öğretim teknolojilerini kullanmaya yönelik özgüvenleri. Sosyal Bilimler Dergisi, 5 (9), 77-87.

Bursal, M. ve Yiğit, N. (2012). Fen ve teknoloji öğretmen adaylarının bilgi iletişim teknolojileri kullanımı ve materyal tasarımı öz-yeterlik inanışları. Kuram ve Uygulamada Eğitim Bilimleri, 12 (2), 1073-1088.

Büyüköztürk, Ş. (2011). Sosyal bilimler için veri analiẓi el kitabı. (15.Baskı). Ankara: Pegem A Yayıncilik.

Büyüköztürk, Ş., Akgün, Ö., Karadeniz, Ş., Demirel, F. ve Kılıç, E. (2012). Bilimsel araștırma yöntemleri. Ankara: Pegem A Yayıncilık.

Çokluk, Ö., Şekercioğlu, G. ve Büyüköztürk, Ş. (2010). Sosyal bilimler için çok değģskenli istatistik. Ankara: Pegem A Yayıncilik.

Demirel, Ö. ve Altun, E. (2007). Öğretim teknolojileri ve materyal tasarmı. Ankara: Pegem A Yayınc1lik.

Hooper, D., Coughlan, J. and Mullen, M. R. (2008). Structural equation modelling: Guidelines for determining model fit. The Electronic Journal of Business Research Methods, 6 (1), 53- 60. Retrived from ejbrm.com

$\mathrm{Hu}, \mathrm{L}$. ve Bentler, P. M. (1999). Cut off criteria for fit indexes in covariance structure analysis: Conventional criteria versus new alternatives. Structural Equation Modeling, 6 (1), 1-55.

Hu, P. J., Clark, T. H. K. and Ma, W. W. (2003). Examining technology acceptance by school teachers: A longitudial study. Information and Management, 41 (2), 227-241.

İşman, A. (2011). Öğretim teknolojileri ve materyal tasarmı. Ankara: Pegem A Yayıncılık. 
Bakaç, E., \& Özen, R. (2015). Materyal tasarımı Öz-yeterlik inancı ölçeği: geçerlik ve güvenirlik çalıșması. International Journal of Human Sciences, 12(2), 461-476. doi: 10.14687/ijhs.v12i2.3341

Kaya, Z. (2006). Öğretim teknolojileri ve materyal geliştirme. Ankara: Pegem A Yayıncilik.

Kline, R. B. (2005). Principles and practice of structural equation modeling: A researcher's guide. London: Sage Publications.

Kolburan Geçer, A. (2010). Teknik öğretmen adaylarının öğretim teknolojisi ve materyal geliştirme dersine yönelik deneyimleri. Yǚz̈ncü Yal Üniversitesi, Eğitim Fakültesi Dergisi, 7 (2), 1-25.

Özüt, A. ve Tuncer, M. (2012). Sınıf öğretmeni adaylarının eğitsel internet kullanımına yönelik öz yeterlik inançlar1. International Periodical For the Languages, Literature and History of Turkish or Turkic, 7 (2), 1079-1091.

Sarıçoban, A. ve Tavil, Z. M. (2012). Yabancı dil öğretiminde ögretim teknolojileri ve materyal tasarmı. Ankara: Anı Yayıncilik.

Seferoğlu, S. ve Yağc1, E. (2001). Öğretim teknolojileri ve materyal gelisstrime. Ankara: Pegem A Yayınc1lik. Selvi, K. (2012). Ögretim teknolojileri ve materyal tasarmı. Ankara: Anı Yayınc1l1k.

Sever, R. (2011). Ögrretim teknolojileri ve materyal tasarmı: Tasarm örnekleri. Ankara: Anı Yayıncilık.

Senemoğlu, N. (2007). Gelişim ögrenme ve ögrretim. Ankara: Gönül Yayınc1lık.

Şencan, H. (2005). Sosyal ve davramıssal ölçümlerde güvenirlik ve gȩ̣erlilik. Ankara: Seçkin Yayıncilık.

Tavşancıl, E. (2010). Tutumlarn ölçülmesi ve spss ile veri analiz̨i. (4. Baskı). Ankara: Nobel Yayın Dağitım.

Uyangör, M. S. ve Ece, D. K. (2010). The attitudes of the prospective mathematics teachers towards instructional technologies and material development course. The Turkish Online Journal of Educational Technology, 9 (1), 213-220. Retrived from www.tojet.net.

Uzunboylu, H. (2011). Ögrretim teknolojileri ve materyal tasarmı. (2. Baskı). Ankara: Pegem Akademi.

Ünsal, Y. (2011). Öğretim teknolojileri ve materyal tasarımı derslerinde üretilen üç boyutlu nesnelerin değerlendirilmesinde kullanılabilecek bir ölçek önerisi. 2nd International Conference on New Trends in Education and Their Implications Kongresi Kongre Kitabr (ss.817-822). Antalya.

Varank, İ. ve Ergün, S. S., (2009). Uygulamaya dayalı ögretim teknolojileri ve materyal tasarımı becerileri ölçeği geliştirme. M.Ü. Atatürk Eğitim Fakültesi Eğitim Bilimleri Dergisi, 29, 173185.

Yalın, H. İ. (2007). Öğretim teknolojileri ve materyal geliştirme. (19. Baskı). Ankara: Nobel Yayın Dağıtım.

Yanpar, T. (2009). Öğretmen adaylarının portfolyoları üzerinde grup olarak yaratıc1lı temelli materyal geliştirmenin etkileri. Eğitim ve Bilim, 34 (153), 83-98.

Yanpar, T. (2011). Öğretim teknolojileri ve materyal geliștirme. Ankara: Anı Yayınc1l1k.

Yıldız, R. (2004). Öğretim teknolojileri ve materyal gelistirme. Konya: Atlas Kitabevi.

\section{Extended English Abstract}

Activities in the classroom effect preservice teachers' self-efficacy beliefs in a positive or a negative way. For this reason, educational applications musn't be constructed only on acquiring knowledge or skills, but on the effects of educational activities students' self efficacy beliefs about their abilities; and it's required to form a learning environment based on cooperation, instead of a competitive classroom environment (Bandura, 1997). It is thought that, for the instructional technologies and material design course, baring in mind those principles would effect preservice teachers' beliefs of self-efficacy in a positive way, therefore it would lead the preservice teachers to be more successful in instructional technologies and material design course and would design authentic materials. When literature reviewed on instructional technologies and material design course by the 
researcher, it's seen that researchers generally focused on self-efficacy beliefs of technologhy, computer and internet use (Aşkar, 2004; Bircan, 2012; Özüt ve Tuncer, 2012).

Materials are one of the indispensible elements for students for a beter perception and learning of the lesson. Thanks to the teaching conducted with materials, students are involved in the learninig process by using multiple senses and experiences permanent learning (Seferoğlu ve Yağc1, 2001; Yalın, 2007). As a result, teachers need to know to design materials for creating such a learning environment. In this context, the purpose of this research is to develope an instrument that can determine preservice teachers' self-efficacy beliefs on designing materials.

In the first stage of developing the material design self-efficacy belief scale, the literature was reviewed by the resercher (Aşkar, 2004; Bursal ve Yiğit, 2012; Ünsal, 2011; Varank ve Ergün, 2009; Yanpar, 2009). A first draft of 74 item scale was formed after examining of Education Faculty curriculum and Instructional Technology and Material Design course books (Demirel ve Altun, 2007; İşman, 2011; Kaya, 2006; Sarıçoban ve Tavil, 2012; Seferoğlu ve Yağc1, 2001; Selvi, 2012; Sever, 2011; Uzunboylu, 2011; Yalın, 2007; Yanpar, 2011; Y1ldız, 2004).

In the second stage the draft scale presented to the fifteen measurement and evaluation, curriculum development and instructional technology field experts to take their opinion. Some items were eliminated according to expert opinions, some items were corrected and draft scale was reduced to 53 items. The statements in the scale were classified as five point likert-type format such as "strongly disagree", "disagree", "neutral", "agree" and "strongly agree".

The participants of the study were 300 preservice teachers who were studying at Abant Izzet Baysal University in academic year 2013-2014 and who had already taken the Instructional Technologies and Material Design course. The participants were selected by using random sampling method. 203 of the preservice teachers who participated in the research were females and 97 of them were males. The data were analyzed through SPSS 22 and Lisrel 8.51 programs.

In the third stage, the construct validity of the scale was tested by conducting exploratory and confirmatory factor analysis to decide whether the scale had one dimension or multi dimensions and if the scale had multi dimensions to see which items were combined under which dimensions to prove the construct validity of the scale. Kaiser-Meyer-Olkin coefficient and Barlertt Sphericity tests were conducted to determine the suitability of the data for the exploratory factor analysis. Kaiser-Meyer-Olkin value was found 0,93 and chi square was found 8074,24 ( $\mathrm{df}=1378, \mathrm{p}=, 000$ ). The values showed that data was appropriate for the exploratory factor analysis. Principal Components Factor Analysis method and varimax rotation technique were used to factor analysis. Items which have lower than ,32 factor load were excluded from the material design self-efficacy beliefs scale. It was seen that item factor loadings varied between .51 and .74 . At the end of the exploratory factor analysis, a three-factor scale structure was reached. The first dimension were called as "material design on the computer" and formed 12 items, second dimension were called as "three dimensional material design" and formed 7 items and the last dimension were called as "two dimensional material design" and formed 6 items.

Confirmatory factor analysis was used in order to test whether exploratory factor analysis results were appropriate. When the confirmatory factor analysis results examined, it was seen that ki-kare value $\mathrm{X}^{2}=654.62, \mathrm{~N}=381, \mathrm{sd}=272, p=0.00$. When ki-kare value and sd were proportioned each other, it was found $2,40\left(\mathrm{X}^{2} / \mathrm{sd}=654.62 / 272\right)$. When $\mathrm{X}^{2} /$ sd rate were calculated under 3 , it was presented perfect compliance (Kline, 2005). This value show that the model is give excellent level of compliance. Furthermore, other goodness-fit index (RMSEA $=.061, \mathrm{NFI}=.95$, NNFI $=.95$ $\mathrm{CFI}=.95, \mathrm{IFI}=.90, \mathrm{RFI}=.93, \mathrm{RMR}=.052, \mathrm{GFI}=.90$ ve $\mathrm{AGFI}=.93)$ show that the model is give good level of compliance. Because it is stated that acceptable fit values for AGFI, GFI, NFI, CFI, IFI must be .90 or higher, and for RMR and RMSEA must be 0.08 or lower in the goodness of fit indexs (Bentler ve Bonett, 1980; Hooper, Coughlan ve Mullen, 2008; Hu ve Bentler, 1999).

It was determined that corrected-item total correlations of scale took value between 0,51 and 0,67. T-test was used for the significance of the difference between item points of lower $27 \%$ 
group and upper $27 \%$ group compared to the total points. When item analysis examined, it was seen that there was a significant difference between mean score the lower $\% 27$ group and the uppper $\% 27$ group according to the unrelated t-test results. Consequently, it also said that material design self-efficacy beliefs scale had a internal consistency.

As a result of factor and item analysis was obtained final scale consist of 25 items. The cronbach alpha reliability coefficient was calculated as 0,92 and for dimension as 0,89,0,82 and 0,79 , respectively. According to Şencan (2005) it was seen enough 0,70 coefficient of internal consistency for the scientific studies, 0,85 coefficient of internal consistency was sough in the ability and interest type researches. In this context, it was said that the scale has a internal consistency and an acceptable level of reliability. This results show that this scale can be used to measure as an appropriate measurement tool of the preservice teachers' material design self-efficacy beliefs. 